AGRICULTURE AND BIOLOGY JOURNAL OF NORTH AMERICA

ISSN Print: 2151-7517, ISSN Online: 2151-7525, doi:10.5251/abjna.2012.3.9.345.353

(C) 2012, ScienceHu $\beta$, http://www.scihub.org/ABJNA

\title{
Risks and uncertainties in food production and their implications for extension work in Nigeria
}

\author{
${ }^{1}$ Donye, A. O. and ${ }^{2}$ Ani, A. O. \\ ${ }^{1}$ Department of Agricultural Economics and Extension, Adamawa State University, Mubi \\ ${ }^{2}$ Department of Agricultural Extension Services, University of Maiduguri
}

\begin{abstract}
This paper examines the risks and uncertainties in food production and their implications for extension work in Nigeria. It also discusses some of the factors constituting uncertainties that limit agricultural production and productivity. These factors include, inter alia, land, labour, farm implements and inputs, market systems and government policies. On the other hand, weather risks, biological risks, technical risks and economic and social risks were discussed as other circumstances which greatly reduce the values of agricultural produce and products in terms of quality and quantity. Some risk mitigation and coping strategies which were noted as important ways of reducing crop losses include wiping out the sources of infection, use of disease-resistant plants for crop production and seed propagation, practicing good crop rotation and plant association, use of chemical products and growing crops in mixture. Some of the implications noted for extension work require that extension workers should move beyond simply providing farmers with information on food production and standardized technological packages. They should also provide advice and guidance that facilitate communication and coordination among many different stakeholders in natural resource management and market supply chains. Agricultural extension workers should be able to assist farmers in developing a range of agricultural production options. Extension workers and government should strengthen the existing village-level marketing options. They should analyze the marketing seasons, interact with the people involved in marketing and the provision of transportation facilities and thus, advise farmers accordingly. The recommendations made include, among others, the need for the Government of Nigeria to create and maintain the infrastructure required for agricultural development, ensure that research and extension services, input supply and credit arrangements, marketing structures and price system as well as communication and transport networks are all properly put in place.
\end{abstract}

Key words: Risks, Uncertainties, Food Production, Implications, Nigeria.

\section{INTRODUCTION}

There are a number of risks and uncertainties that are associated with food production, which greatly impede the effort of farmers in terms of their agricultural production and productivity. Risk in agricultural food production is defined as an uncertainty (i.e. imperfect knowledge or predictability) because of randomness. It is regarded as the probability of losses resulting from incomplete control over the processes with which farmers are concerned (OECD, 2000). The sources of these risks and uncertainties in food production include, inter alia, the technical, natural, commercial and financial aspects (Horace, 1959). According to him, the technical risks are those which comprise failure of farming methods, storage and processing, and also from imperfections in the transport systems. The natural causes of risk include losses due to pests and diseases, perishing of products as well as those due to adverse or unfavourable weather conditions. Commercial risks, on the other hand, relates to price fluctuations, which tend to be increased due to long gestation period.

Carroll and Samwick (1995) opined that farmers face income risk when the future path of their expected income stream is not certain, and that it is the deviation of future income stream from its expected path. Other circumstances that constitute risk to rural farmers are: highly erratic rainfall, commodity price fluctuations, poorly functioning or missing markets for inputs and outputs, unexpected changes in policies, unstable government and armed conflicts (Lire et al., 2000). These are forces that farmers have to contend with while making decisions. 
The African food crisis is much debated, hard to explain in all its complexity and difficult to overcome. Land shortages, low land productivity and low farming capacity due to persistent poverty are common explanations to the low food production restricting increased food security (World Bank, 2007). Indigenous food production systems involve complex processes of producing food from diversified agro-ecological environments in order to meet the nutritional requirements of the local people. The demand for agricultural labour could be said to have created a shift from a labour-intensive cropping pattern to one of extensive cropping in many agricultural regions of Nigeria. This has led to a substantial reduction in the area of major food crops such as rice, maize, sorghum and millet. In addition, rapid urbanization rates have forced marginal farmers to dispose of their lands for non-agricultural purposes. Thus, in spite of a major thrust to increase agricultural production by the farmers, shrinkage in the area under production of major food crops has become one of the causes of uncertainties that need much attention.

This paper, therefore, discusses some of the risks and uncertainties encountered by farmers in food production and their implications for extension work in Nigeria. Therefore, the discussion is made on the following:

i. Examples of Factors Associated with Uncertainties in Food Production

ii. Risks and Uncertainties in Food Production

iii. Mitigation Strategies in Uncertain Food Production Environment

iv. Implications for Agricultural Extension Workers

v. Conclusion

vi. Recommendations

Some of the Factors Associated with Uncertainties in Food Production: The farmer has specific resources at his disposal called production factors, and the main ones are: land, water, crops, labour, farm implements, and money. These must be combined on the farm to ensure a meaningful agricultural production. Farming involves suiting production factors as carefully as possible to the goals chosen, but at the same time, being wary of methods which simply exploit production factors and ignore the need to preserve and regenerate them for the future. These include:

Land: Farm production depends on both the extent and quality of the farmland. Farmlands can only be cultivated if they are watered and properly fed. Soil feeding is ensured by manure from organic waste, chemical fertilizers sold commercially or by the decomposition of green crops buried in the ground. Land constitutes a very high degree of uncertainty among farmers in rural societies. The potentiality of food production is largely determined by the availability, or otherwise, of land. Due to many reasons, land availability has been decreasing in many rural farming communities today. For instance, land shortage in Zimbabwe Communal Areas started from the 1930s when peasants were evicted by colonizers from the surrounding fertile areas and moved into Chiweshe reserve (Munyaradzi, 1988 and Johnson, 1964).

Steen (2010) also reported that in Zimbabwe, interviews indicate changes in the general access to land at the creation of the reserve. This, according to him, contradicts the general wisdom which suggests that women have always been allocated land through their husbands. He argued that before the creation of the Chiweshe reserve, married women could be allotted land in their own right alongside their husbands. However, after the creation of the reserve, women were allotted a small garden through their husbands. Supposing control of land is a determinant of production output, the practice reinforced by colonial administrators may constrain production today. Therefore, an important finding is the insecurity and uncertainty in the process of land allocation.

Kenga et al. (2002) noted that in Sudan-Sahel zone of Cameroon, high growth and large number of rainfall deficit years have encouraged extensive arable farming and heightened the competition between grazing and cropping systems. The cultivation of marginal lands and changes in farming systems (e.g. no or shorter fallows) have rendered farmers more vulnerable to climatic risk. In most areas, land allocation to agricultural production is hindered by lack of exclusive use right and land tenure insecurity.

Crops/Plants: Farming is organized round the plants grown. Everything the farmer does is aimed at satisfying the needs of the plants in order to obtain the highest possible yields. Agriculture is characterized by the number of plants cultivated and by the diversity and quality of the produce destined for consumption. The type of the agriculture practiced therefore, depends for instance, on whether the plants cultivated are trees or herbaceous plants, or 
whether they live for many years (perennial or long living plants) and seasonal or annual crops.

Water is an indispensable prerequisite for the development of agriculture just as it is for human life. It must be present at the right time in the life cycle of these crops or plants, and in sufficient quantity. In most cases, especially in the rural areas, rain provides the water needed for agricultural purposes. Sometimes, however, the farmer controls the water supply to his fields. He irrigates the land and taps water at some distance from his fields and uses it to water his crops. In many parts of Africa, more especially in the Sahel, the lack of water limits agricultural production because rainfall is usually inadequate and erratic. The farmer must therefore, realize how important it is to discover which plant varieties suit him best in quantity, quality and cropping system.

Kenga et al. (2002) reported that in the Sudan-Sahel zone of Cameroon, for example, cropping systems in the two provinces are mainly based on sorghum, cotton and maize. On the south-north axis, the importance of maize decreases and that of sorghum increases, while cotton is the major cash crop regardless of geographical position. In the region, the major food crops are sorghum, maize, groundnuts and cowpea. The minor crops include sesame, vegetables and bambara-nuts grown in a variety of intercrop. Sole crops are predominant in the southern sub-zone where the use of herbicides for weed control is important. In the low rainfall zone, the most important cropping system observed includes: cotton/maize; cotton/sorghum; cotton/cowpea; sorghum/groundnut; sorghum/cowpea; millet/groundnut and millet/cowpea. The three-crop system and other patterns are most common in the southern sub-zone with higher rainfall, more fertile lixisols and low population density. These are cotton/maize/groundnut or sorghum; cotton/sorghum/vegetables; maize/cotton/vegetables; sorghum/groundnut/cotton; sorghum/cowpea/cotton and sorghum/groundnut/cowpea. Other important enterprises specific to some location include: muskuwaari/cotton/sorghum and cotton/sorghum/muskuwaari in the northern zone. Rice and muskuwaari are important in the low land area.

Labour: Cultivating land for food production is a demanding work which depends on the seasons and the life cycle of the crops grown. Since farm work is seasonal, at certain times of the year, the farmer has a great deal of work, especially during the sowing season or at harvest time. At other times, however, there is not much work to be done in the fields. The cultural methods used and the degree of sophistication of the implements used may influence the availability, quantity and ease of work.

Dalton (1982) indicated that at household level, the resource poor farmers consider labour force as one of the most limiting factors. The amount of land area a family can cultivate is initially constrained by the amount of labour available to it. Any expansion of production must come either from an increase in the amount of labour from sources outside the family or from an increase in productivity through technological innovation of the existing labour sources. According to him, the use of animal traction to prepare fields for planting is the most common technological improvement both encouraged by development interventions and employed by farmers. All of these, considering the general resource poor conditions of majority of rural farmers and societies, are production requirements that leave the farmers in obvious state of diverse uncertainties and crucial decision. This is because, money is needed to buy many of the production factors (for instance, chemical fertilizers, pesticides, machineries, traction power and fuel for machines) which cannot be found or made on the farm. Self-sufficient farming carried out by the farmer for family needs requires little money. On the other hand, some intensive farming systems, organized solely for the sale of produce, require large amounts of money because they use many machines, fertilizers, pesticides and other production factors.

Farm Implements and Inputs: The farmer cannot do his work without implements. These have different levels of sophistication. They can be operated manually, by animal traction or by a motor or a machine. The more sophisticated the implements, the less likely they are to be produced by the farmers or village inhabitants. Simpler implements can be made by the people or by local craftsmen. Implements bought commercially presuppose reserve funds. Dalton (1982) reported that the inherent characteristics of agricultural inputs influence the way they can be used. The fact that they complement each other means that it is quite possible that production will be limited by the unavailability of one particular input. Therefore, the response in output to a change in the level of a single input will depend on the level and variation in the level of all other inputs. Farmers could also be confronted with lack of the technical knowledge about the existence of these production complexities. Even though they might 
have been taught by extension workers on the importance of the inputs, the lack of and/or the untimely delivery of these inputs to them might constitute a great measure of uncertain food production conditions.

In a field assessment study carried out in Sidama zone in Ethiopia by the United Nations Emergencies Unit for Ethiopia (UN-EUE, 2002), it was reported that minimum use of improved farm inputs generally threatened crop production. The report indicated that when the Ethiopian government started to distribute farm inputs to farmers on credit, farmers of Sidama zone were intensively using improved inputs such as chemical fertilizers and improved seeds for their agricultural production, especially for food crops such as maize. A drought in 1999 affected and damaged all crops (annuals and perennials) and there was no good harvest in the year despite most farmers' intensive use of improved farm inputs on credit basis. As a result many farm households faced food shortage and were unable to pay back their credits. This made the government to relinquish its farm input credit programme. Thus, they were left to buy the inputs by themselves. The farmers therefore, used degenerated second and third generations of hybrid maize, which resulted into a yield reduction of $30 \%$ in the year 2000.

Considering the scenario reported by the UN-EUE, it could be seen that even with the use of all recommended inputs, farmers are still operating under uncertain production conditions at the mercy of the nature of rains, weather and other natural hazards, particularly in the case of rain-fed agriculture. On the other hand, assuming there are promising rainy seasons and weather conditions, lack of money and or recommended inputs could equally force the poor resource farmers to have poor yields and subsequent food shortages. These are all serious uncertain conditions that greatly impede food production in many nations, especially the developing countries including Nigeria.

Marketing and Market Systems: Lire et al., (2000) also indicated that poorly organized market systems are one of the circumstances constituting uncertainties in food production. According to them, market systems have an overriding influence on the development of agriculture. It implies therefore, that the market or its substitute has to work on an organized manner if farmers are to overcome food production uncertainties associated with marketing of their farm produce, inputs and implements. For instance, inputs must be available and outlets must exist for the products of agriculture. In many parts of the developing world, including Nigeria, this may not be the case. For instance, transportation means may be a serious impediment because of the bad nature of roads or inadequate network of roads as well as shortage of vehicles. All of these constitute great uncertainty in the food production environment. Thus, the ever changing and unstable price of produce, products and inputs, organization or disorganization of markets, insufficient technical knowledge, the location of farms from access roads etc., are serious sources of uncertainties in food production.

In Nigeria, prior to the introduction of Structural Adjustment Programme (SAP), the marketing arrangement for agricultural produce was categorized into two:

i. Domestic Trade: This was handled mainly by the private sector, with relatively little or no government intervention in the operation of the market.

ii. Export Trade: This was the exclusive preserve of the government, and so it attracted considerable attention of the government by way of policy.

The main strand of marketing and pricing policy was that the then commodity boards fixed producer prices for agricultural commodities. The activities of these commodity boards in Nigeria, according to the CBN/NISER (1992) reports, prior to their abolition in 1986, were major sources of disincentives to farming.

Agricultural Input Pricing Policy (IPP), prior to SAP, focused on the provision of subsidies on farm inputs such as chemical fertilizers, machineries, seeds, pesticides and credit. With policy reforms, the subsidies on input were substantially eliminated. While this may not have augured well for the overall improvement in the productive capacities of the rural small-scale farmers, it however served to reduce the policy bias which empowered urbanites to corner the subsidy meant for all. The point of emphasis here, therefore, is that such policy changes have always left the farmers and rural societies uncomfortable in the choice of their production systems.

Low price of farm produce due to poor quality or bad market situations has also been greatly responsible for the failure of farmers to cover the production costs in many cases. This discourages farmers from continuing to produce food and cash crops surrounded by such uncertain food production conditions. They may not like to take the risk of 
producing such crops because of the fear of producing at a loss. For instance, the physical performance and condition of crops may be good, but may also be deceiving as the crops might fail to attain good grain setting at maturation stage. Thus, low market prices for crops could induce low purchasing power of farmers, and hence, create a serious state of uncertain production system choice as well as economic indecision.

Rajasekaran (1992) reported that fluctuating markets also constitute a great deal of uncertainty to farmers in rural societies in India. For instance, he stated that an uncertain market for duck egg is one of the predominant constraints in duck fish production system in South India. Searching for market outlets in the towns has become difficult for the rural youths. The narrow range of consumers for duck eggs causes these marketing constraints. The women labourers are increasingly discouraged regarding this situation. Moreover, because the surplus eggs are sold through only three channels, it is very difficult to find a dependable market for the commodity. Farmers' markets provide space for direct contact between local growers and shoppers and are an effective first step for communities seeking to develop a marketing outlet to promote stronger local food systems.

Government Policies: In many third world countries, development-planning strategies give little or no consideration to rural development. Rural areas and their inhabitants are often neglected as plans emphasize urban growth rates. These rural settlements, however, should be viewed for purposes of development planning as "rural people" and the geographic segment in which they live should be taken in conjunction with those urban areas and people with whom they share close economic and social interdependence (McDougall, 1987). He also argued that policy makers did not recognize the significance of the indigenous knowledge base of the rural people, nor did they provide them with adequate incentives. The smallholder sector was confronted with ill-designed plans, which did not provide adequate coordination between local, district and regional levels of administration. Past policies, according to him, ostensibly intended to help rural people were nothing more than schemes to develop urban centers at the expense of the rural areas. The kind of pricing policies pursued by the statutory corporations, particularly the marketing boards, were means by which the rural farmers were made to subsidize programmes aimed at the urban centers.
According to CBN/NISER (1992) reports, prior to the policy reforms in Nigeria, trade policy was inward looking and perceived mainly in terms of protection for the growing of domestic manufacturing industry that was largely import dependent. Little consideration was given to the stimulation of export of both agriculture and domestic products. Nothing was done to protect domestic agriculture. For several years, large import of food, especially grains such as wheat, rice and maize were allowed into the country at very cheap prices. This eroded the competitiveness of domestically produced grains, a situation that acted as a major disincentive to farmers. This therefore, created a state of uncertainty to famers in rural societies. They would not produce such crops on large scale for fear of losses in produce due to lack of good storage facilities and also the possible sale at lower prices.

Risks and Uncertainties in Food Production: Farming, in many instances, is a hazardous occupation because, to some extent, it faces many risks. It is risky because results depend, to an alarming extent, on many factors over which the farmer has no control. He operates under uncertain conditions and factors which he can only influence to a minimal degree. For instance, he does not determine rainfall; he cannot contain a sudden attack of locusts; he cannot stop the outbreak of serious diseases fatal to his crops etc. Under such uncertain circumstances, farmers need to develop some strategies that could help minimize the effects of such risks in the event of their occurrence. According to Dupriez and Leener (1988) and Dalton (1982), the risks farmers face fall under the following four major headings:

Weather Risks: Weather hazards subject farming to chance effects. For instance, if rainfall is inadequate or untimely, plants dry up and yields are in jeopardy. At times, sudden hurricane flattens plants to the ground, which can cause enormous losses in crop yield. A spell of exceptionally cold weather destroys flowers and young fruits. In fact, there are many varied ways of combating weather risks, but there is no adequate or full proof way of protecting crops from bad weather. According to Dupriez and Leener (1988), rain calendars were studied in detail and two particular aspects of weather hazard connected with rainfall were identified as:

(a) Rains may be inadequate for a cultural season taken as a whole. 
(b)

Rains may be unreliable and, above all, they may be totally lacking at crucial times in the plant life.

It then follows that drought inevitably follows lack of rain and, with it, damage to plants that are not at the end of their life cycle at such times.

Biological Risks: Plant health is subject to certain hazards. They may be attacked by microorganisms carrying diseases. They may be eaten by caterpillars, slugs, insects and rodents. Monkeys, loose animals and elephants, for instance, can devastate crops. People also cause devastation, for example, by lighting uncontrolled fires. Other biological risks include pest attacks, rotting and fermentation or damage caused by wandering animals.

Economic and Social Risks: These risks spring from the economic and social environment of farmers' farms. The famer is not sure of finding buyers for his produce after the harvest, or the market prices might have slumped when his produce is up for sale. Production factors such as manpower, fertilizer, seeds, tools, machinery may also be in short supply when they are most needed for the planting season. The cost of production factors may shoot up or workers fall ill. All of these pose serious risks to farmers' food production enterprises.

Technical Risks: A mechanical breakdown may occur at a critical time of food production. For instance, when a plough part breaks, an engine stops working etc. If the spare parts are not available, agricultural food production activities may suffer setback because the farmer will be forced to halt his cultural operations. Uncertainty about the future works both ways. For example, a farmer can win or lose depending on the outcome of events. According to Dalton (1982), constraints of various other kinds also limit the farmer's freedom to make changes in the process of food production. These may consist of simple identities such as the fact that the demand for resources cannot exceed the supply of the resources. Constraints are also imposed by the legal system, moral values and also by the technical relationships that exist between activities as is the case in rotational practices.

According to Dupriez and Leener (1988), farmers are faced with many food production uncertainties in rural areas. These prevent them from acting freely in accordance with their food production wishes. In such circumstances, they have to take some innumerable and highly diversified risks and uncertainties into consideration. For example, some of these are imposed by the amount of arable land available, the quality and quantity of the seeds etc. Other causes of uncertainties in food production are the climate, diseases in man, diseases in crops, diseases in cattle, the quality of the implements used by farmers, and so on. For instance, several production factors may be missing at the same time, and if one key factor should prove deficient, say water or seeds, it may be impossible for farming operations to continue effectively and for the farmers to perform efficiently. This is because the farmers have little or no control over these factors. The following are examples of the uncertainties in food production which require informed decisions on the part of the farmers to be overcome:

(i) If rainfall is inadequate at the beginning of the rainy season, seeds dry up and the harvest is bound to be poor. Water is the restricting factor in this case.

(ii) If harvest is plentiful and there are not enough workers to bring in the produce, there is a labour shortage or restriction. This means that the workers on the farm are unable to harvest all the produce, particularly at the right time.

(iii) Perhaps a machine will speed up the work of the harvesters, but there is no money to buy or hire it. This is a money constraint.

Risk Mitigation, Aversion and Coping Strategies: Rural farmers in various places have been reported to adopt some risk management and coping strategies in response to some uncertainties and risks that are encountered in their agricultural activities. Other studies have reported various other coping strategies adopted by farmers in mitigating the risks and uncertainties they encounter in terms of labour in some parts of the world. For instance, Kochar (1995) reported that labour supply adjustment rather than asset or other strategies is the main strategy used in India to avoid labour related uncertainties. Moser (1998), in the findings of his study in Zambia, reported children being taken out of school in response to adverse income shocks to work.

Plant diseases are caused by a wide range of pests such as insects, worms, fungi, bacteria, viruses, birds, rodents and sometimes other mammals as well. The following practices are recommended for farmers to use in order to avoid, mitigate or minimize such risks and uncertainties as might be determined by specific circumstances: 
i. Sources of infection should be wiped out e.g. places, usually the nests.

ii. Choosing disease-resistant plants for crop production and seed propagation.

iii. Practicing good crop rotation and plant association should be maintained.

iv. The use of chemical products should be adopted, particularly if the farmer can afford them. This is a good means of fighting diseases and disease carriers.

v. Growing crops in mixture is also another inexpensive way of tackling the problems of pests where the farmer cannot afford pesticides.

In situations whereby farmers are confronted by economic and technical risks, some measures could be taken in order to reduce the uncertainties associated with food production activities. For instance, when a farmer falls ill, when prices of inputs and outputs plummet, when unforeseeable expenses have to be covered, when land and money are short, and when transport services become inadequate etc. If cases like these occur, whether on farms, in villages, over a region or even nationwide, farmers can try the following as mitigation measures:

i. Adapting and improving agricultural methods;

ii. Setting up reserves of food and money;

iii. Promoting mutual help schemes; and,

iii. Making farm and village activities as varied as possible.

Implications for Agricultural Extension Workers: The challenges faced by the smallholder farmers are both numerous and enormous if they are to enter the cash economy. They will need strong support from well trained agricultural extension professionals with appropriate knowledge and skills to drive the agricultural modernization process.

Extension workers and related organizations and agencies also need to make concerted and purposeful efforts to ensure that rural feeder roads and linkages are adequately provided. This could be achieved through their direct or indirect intervention in the national agriculture and agricultural extension policies in Nigeria. Extension workers should also know that if such reasons and factors that pose uncertainties and risks in food production to the rural farmers are not given deserved and adequate attention, by implication, all other efforts being made may end up being wasted efforts. The knowledge of the risks and uncertainties confronting rural farmers in food production will enable all stakeholders, especially agricultural extension planners, agricultural programme developers and farmers to minimize the effects of the natural risks and uncertainties and probably eliminate those that are manmade.

Extension workers should move beyond simply providing farmers with information on food production and standardized technological packages. They should also provide advice and guidance that facilitate communication and coordination among many different stakeholders in natural resource management and market supply chains. Agricultural extension workers should be able to assist farmers in developing a range of options to address uncertainties brought about by climate change, government policy changes that can negatively affect the entire agricultural value chain. This will involve training farmers on how to add value to their agricultural produce through appropriate storage practices, processing, marketing and similar value addition activities. The focus on technical aspects of agricultural production at the expense of agricultural value chain as well as other new emerging issues should be reconsidered by extension workers. They should alert farmers and farmer organizations on the need to increasingly engage in activities that add value along the agricultural value chain. Extension workers should educate farmers to move in the direction of commercial agriculture rather than subsistence agriculture. They should also encourage and assist farmers to involve themselves in livelihood diversification activities that are not directly agriculture-based or agriculture-related. This will enable the farmers to attain some level of livelihood security and coping capabilities against risks and uncertainties.

There is a need for extension workers to enhance their educational delivery through the use of Information and Communication Technologies in their operational framework. This will scale up information sharing and also keep farmers abreast with market situations in terms of prices of commodities, availability or otherwise of inputs and implements etc. 
Conclusion: The paper discussed risks and uncertainties encountered by farmers in food production and their implications for extension work in Nigeria. Government policies, lack of enabling environment in terms of infrastructure, insecurity and uncertainty in the process of land allocation, drought, erratic rainy seasons, climate change and unstable marketing systems are some of the major uncertainties farmers encounter in food production. Other factors associated with uncertainties in food production are labour, crops/plants and implements and inputs. The fact that farmers have neither control over policy issues nor influence on infrastructure development leaves them in the cloud of uncertainties associated with food production. The risks in food production include, among others, weather risks, biological risks, economic and social risks and technical risks. Some mitigation and coping strategies adapted in some countries include, inter alia, the following:

$$
\begin{aligned}
& \text { wiping out known sources of crop } \\
& \text { infection; } \\
& \text { ii. Use of disease-resistant plants for } \\
& \text { crop production and seed } \\
& \text { propagation; }
\end{aligned}
$$

\section{Recommendations:}

Government should create and maintain the infrastructure required for agricultural development. Government should ensure that research and extension services, input supply and credit arrangements, marketing structures and price system as well as communication and transport networks are properly put in place. In other words, policy guidelines on infrastructure development and operation should be given much attention by government. This will greatly facilitate food production by reducing risks and uncertainties.

Formulating policies that will help to identify, conserve and utilize local food production systems that benefit farmers in rural societies will go a long way in ameliorating the problems due to risks and uncertainties confronting them. Farmers' reaction in managing their farms and in deciding between production alternatives depends on the infrastructure and the economic incentives of the agricultural sector. In addition to establishing a supportive infrastructure, a central concern of government in agricultural development and, by extrapolation, in economic development should therefore, ensure that farmers are continually exposed to attractive production options and conditions. This is very important because farmers, both small-scale and large-scale, react positively and quickly to attractive prices for their produce and products.

Effort should be made by government and extension workers to link institutional markets with small and medium scale producers. Such efforts have the potential to sustain the economic development of farmers in rural societies, enhance the working landscape, maintain diversity and quality in products and also provide linkages among producers, consumers and other food system stakeholders.

Extension workers and government should strengthen the existing village-level marketing options. They should analyze the marketing seasons, interact with the people involved in marketing and the provision of transportation facilities and advise farmers accordingly. These could be some of the initial measures that might be employed to mitigate or minimize the risks and uncertainties being encountered by farmers in food production.

Farmers should be trained to be able to increase food production and productivity, while at the same time maintaining the sustainability of their farming systems by making effective use of knowledge and information which is available from or can be generated by several different sources, such as research institutes, successful farmers and markets.

\section{REFERENCES}

CBN/NISER National Study (1992). The Impact of SAP on Nigerian Agricultural Rural Life Vol. II., Intec. Printers Ltd., Ibadan, Nigeria.

Carroll C. D. and Samwick, A. (1995). "How Important Precautionary Saving"? Review of Economics and Statistics 80 (August). Pp. 410-419.

Dalton, G. E., (1982). Managing Agricultural Systems. Applied science publishers, London.

Dupriez, H. and Leener, P.D. (1988). Agriculture in African Rural communities .Macmillan Publishers Ltd., London. 
Horace, B. (1959): Agricultural Credit in Economically Underdeveloped Countries. A Review $f$ Economic Studies, FAO, Rome, Italy. Pp. 98-110.

Johnson, R. W. M. (1964). An Economic Survey of Chiweshe. Rhodes Livingstone Journal, XXXVI, 82108.

Kenga, R., M'Biandoun, M., Njoya, A., Havard, M. and Vall, E. (2002). Analysis of Constraints to Agricultural Production in the Sudan-sahelian Zone of Cameroon Using a Diagnostic Survey. Actes du colloque 27-31 Mai, 2002 Garoua, Cameroun.

Kochar, A. (1995): Eplaining Household Vulnerability to Idiosyncratic Income Shocks. AEA Papers and Proceedings. American Economic Review, Vol. 85, 159-164.

Lire, E., Jeffery, A. and Harrold, A. (2000). "Changing in Consumption and Saving behavior before and after Economic Shocks: Evidence from Zimbabwe". A Paper Presented at the International Food and Agribusiness Management Association Conference, Chicago, pp.139.

McDougall, E. A. (1987). Sustainable Agriculture in Africa. Africa World Press, Inc. Trenton, New Jersey.

Munyaradzi, N. (1988). Problems of Colonial Peasant Production in Chiweshe with Special Emphasis on the Growth of a Peasant Consciousness on Food and Nutritional Security (Unpublished Ph. D. Thesis, University of Zimbabwe).
Moser, D. (1998): The Asset Vulnerability Framework: reassessing Urban Poverty Reduction Stategies. World Development, Vol. 26 No. 1 p. 2-5.

Organization for Economic Cooperation and Development (2000): Approach to Income Risk Management in OECD Countries. A Workshop on Risks Management, GAR/CA/APM/APRM, Directorate of Food, Agriculture and Fisheries Committee for Agriculture, Paris.

Rajasekaran, B. (1992). An Indigenous Duck-Fish Production System in South India: Impact on Food and Nutritional Security. www.ciesin.org/docs/004-200/004200.html

Steen K. (2010). Why Poor Peasant Farmers Stay Poor: Gendered Drivers behind Stagnating Food Production in Zimbabwe Communal Areas. A paper Presented at African Economic History Workshop, LSE $28^{\text {th }}$ April, 2010

United Nations Emergencies for Ethiopia (UN-EUE, 2002). Uncertain Food Security Situation for Farmers in Sidama Zone due to Lack of Access to Farm Inputs. Field Assessment Mission.

http://www.telecom.net.et/ undpeue/reports/SidamaReport 062002.pdf

World Bank (2007). World Development Report, 2008. Agriculture for Development. XXXVI, 82-108. Washington: The World Bank. 